\title{
Some Factors Affecting the Growth and Sporulation of Chaetomium globosum and Memnoniella echinata
}

\author{
By H. W. BUSTON and S. N. BASU \\ The Biochemical Laboratories, Department of Botany, Imperial \\ College of Science and Technology, London
}

SUMMARY: The influence of certain carbohydrates, nitrogen compounds and accessory substances on the growth and sporulation of Chaetomium globosum and Memnoniella echinata has been studied. It has been confirmed that $M$. echinata needs an external supply of biotin, which has also a slight effect on the growth of Chaetomium globosum. For C. globosum, a very low level of soluble sugar in the medium was essential for the production of perithecia. With adequate biotin, Memnoniella echinata sporulated in the presence of considerable concentrations of sugar, but at low biotin levels no sporulation occurred until soluble sugar approached exhaustion.

Jute extract stimulated growth and accelerated sporulation of Chaetomium globosum; this was not due to the presence in the extract of any of nine well-known B-group vitamins. Jute extract had no more influence on Memnoniella echinata than would be due to its biotin content.

In the course of an extensive survey of the cellulose-decomposing capacity of certain mildew-fungi, which commonly occur on textiles, it was noticed that sporulation in some cases was markedly influenced by the nature of the culture medium employed. Some Chaetomium species, for instance, gave only sterile hyphal growth on ordinary salt-sugar media, whereas in the presence of cellulose vigorous perithecial fruiting was observed. Various factors, physical and chemical, have been reported by previous workers as influencing sporulation in a number of species, and the present studies were undertaken chiefly in order to gain more information concerning the conditions needed to stimulate fruiting of C.globosum Kunze ex Fr. and Memnoniella echinata (Rw.) Galloway.

\section{EXPERIMENTAL}

\section{Materials and methods}

Chaetomium globosum. The strain used was originally isolated from a piece of brown paper found rotting in contact with moist soil, and was maintained on a strip of filter-paper half immersed in Czapek-Dox salt solution.

Memnoniella echinata. The strain was isolated in India from rotten cotton canvas, and was maintained in the same way as the Chaetomium sp. The identity of both organisms was confirmed by the Imperial Mycological Institute, Kew.

The basal medium contained $\mathrm{NaNO}_{3} 2$ g., $\mathrm{KH}_{2} \mathrm{PO}_{4} 1$ g., $\mathrm{KCl} 0.5$ g., $\mathrm{MgSO}_{4} .7 \mathrm{H}_{2} \mathrm{O} 0.5 \mathrm{~g}$., and $\mathrm{FeSO}_{4} .7 \mathrm{H}_{2} \mathrm{O} 0.01 \mathrm{~g}$., in 1 l. water. Occasionally, as indicated in the text, $\mathrm{K}_{2} \mathrm{HPO}_{4}$ replaced the acid phosphate. For solid media, agar (15 g./l.) was incorporated. Sterilization was at $10 \mathrm{lb}$. for $15 \mathrm{~min}$.; incubation was at $30^{\circ}$. 
In the tables, the symbols + to +++ have been used to indicate the amount of growth and sporulation; attempts were made to count the perithecia of C. globosum, but had to be abandoned as the hyphal growth often obscured the perithecia. Colony diameters were used in some cases to estimate growth on agar media, two measurements at right angles being taken on pairs of plates; in liquid media, the dry weight of mycelium was determined.

\section{Source of carbon in the medium}

A low concentration of hexose sugar has frequently been associated with production of spores (cf. Klebs, 1900; Coons, 1916; Robinson, 1926), and any process resulting in exhaustion of sugar in the medium (e.g. prolonged incubation, accelerated respiration, etc.) may finally cause sporulation. The nature of the carbohydrate present has also been thought to affect sporulation, but in some cases this effect seems to have been due merely to the ease with which a polysaccharide is broken down to hexose. In the first tests, which were mainly qualitative, eight different carbohydrates; chosen to represent a range of chemical types, were used as the source of carbon, namely, glucose, maltose, cellobiose, sucrose, starch-dextrin, cello-dextrin, starch and cellulose. All were used in $3 \%$ concentration, except cellulose (a sample purified by refluxing with $1 \%$ ethanolic $\mathrm{HCl}$, followed by $1 \% \mathrm{NaOH}$ and washing), whose concentration was $1 \%$; the basal medium contained $\mathrm{K}_{2} \mathrm{HPO}_{4}$ in place of the acid salt. Table 1 records the growth after 14 days' incubation.

\section{Table 1. Influence of various carbohydrates on growth and} sporulation on solid media

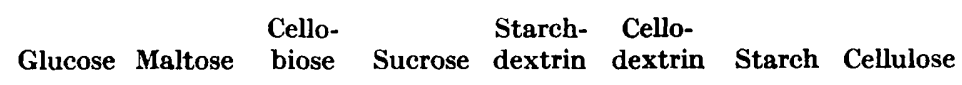

\begin{tabular}{|c|c|c|c|c|c|c|c|c|}
\hline \multicolumn{9}{|c|}{ Chaetomium globosum } \\
\hline $\begin{array}{l}\text { Mycelial } \\
\text { Perithecial }\end{array}$ & $\begin{array}{c}++ \\
-\end{array}$ & $\begin{array}{c}++ \\
\text { Trace }\end{array}$ & ++ & $\begin{array}{c}++ \\
-\end{array}$ & $\begin{array}{c}++ \\
\text { Trace }\end{array}$ & $\begin{array}{c}+ \\
++\end{array}$ & $\begin{array}{l}++ \\
++\end{array}$ & $\begin{array}{c}+ \\
++\end{array}$ \\
\hline \multicolumn{9}{|c|}{ Memnoniella echinata } \\
\hline $\begin{array}{l}\text { Mycelial } \\
\text { Conidial }\end{array}$ & ++ & $\begin{array}{c}++ \\
\text { Trace }\end{array}$ & ++ & $\begin{array}{c}++ \\
-\end{array}$ & $\begin{array}{l}+t \\
t+\end{array}$ & $\begin{array}{c}+t \\
+t+\end{array}$ & $\begin{array}{l}++ \\
++\end{array}$ & $\begin{array}{c}+ \\
++\end{array}$ \\
\hline
\end{tabular}

The effect of varying the sugar concentration was next studied, the results observed after 10 days being recorded in Table 2, whereas Table 3 gives the results of a more detailed study of growth on glucose media, with varying concentrations and over longer periods.

Because sporulation seemed connected with a low concentration of sugar in the medium, whether initially provided or produced by prolonged incubation, the actual sugar concentration at the time of onset of fruiting was determined in some cases. The results (Table 4) showed that with $C$. globosum fruiting did not on any occasion take place until the sugar had almost disappeared from the medium; nevertheless, exhaustion of the sugar did not necessarily induce fruiting, and some other factor must therefore have played a part in the process. With Memnoniella echinata exhaustion of sugar is not essential, for 
Table 2. Effect of varied concentration of sugars on growth and sporulation on solid media

Chaetomium globosum

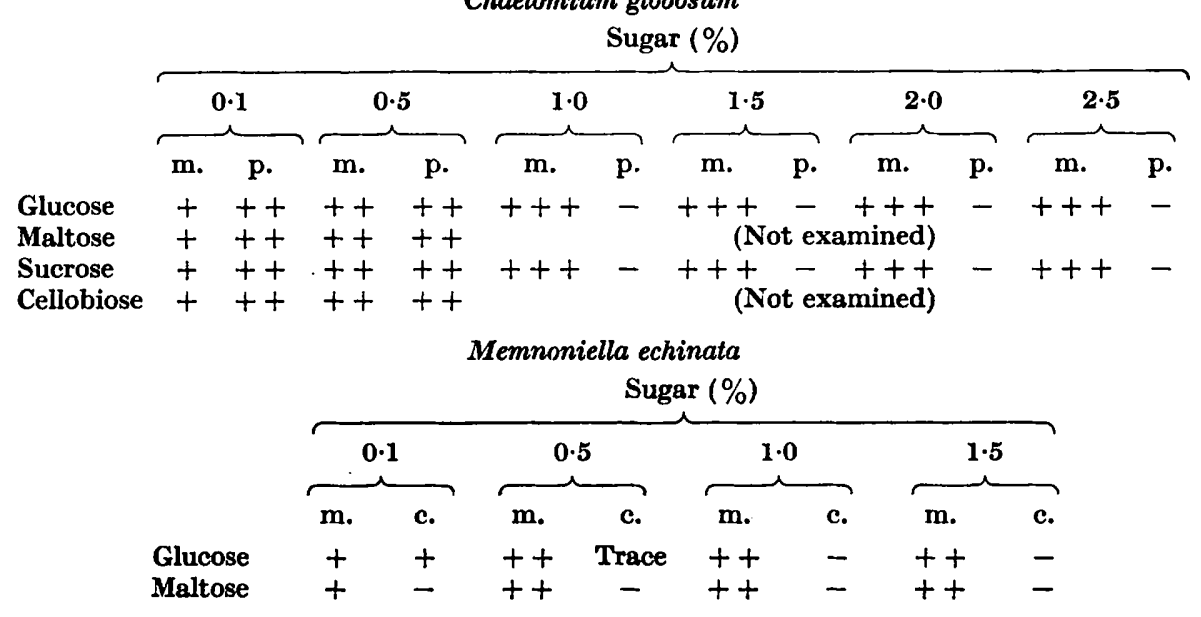

m., p. and c. =mycelial, perithecial and conidial growth.

Table 3. Effect of different concentrations of glucose on growth and sporulation, over varying periods of time, of Chaetomium globosum on solid media

\begin{tabular}{|c|c|c|c|c|c|c|c|c|}
\hline \multirow[b]{3}{*}{$\begin{array}{c}\text { Glucose } \\
(\%)\end{array}$} & \multicolumn{8}{|c|}{ Days } \\
\hline & \multicolumn{2}{|c|}{10} & \multicolumn{2}{|c|}{15} & \multicolumn{2}{|c|}{20} & \multicolumn{2}{|c|}{25} \\
\hline & m. & p. & m. & p. & m. & p. & m. & p. \\
\hline 0.1 & + & ++ & + & ++ & + & ++ & + & ++ \\
\hline 0.5 & ++ & +++ & ++ & $++t$ & ++ & +++ & ++ & +++ \\
\hline $1 \cdot 0$ & ++ & - & ++ & +++ & ++ & $++t$ & ++ & $+t+$ \\
\hline 1.5 & ++ & - & ++ & - & ++ & ++ & ++ & +++ \\
\hline $2 \cdot 0$ & +++ & - & +++ & - & $+t+$ & - & +++ & ++ \\
\hline
\end{tabular}

m. and p. = mycelial and perithecial growth.

when the initial glucose level was high, considerable amounts of sugar remained at the time of sporulation (Table 4). However, the medium for $M$. echinata, unlike that for Chaetomium globosum, contained added biotin, which tests had shown to be an essential factor for growth in liquid media (see p. 165).

\section{Source of nitrogen in the medium}

The influence of different types of nitrogen compounds on the growth and sporulation of $C$. globosum was investigated, in the presence of glucose $(0.5 \%)$, as the source of carbon. The substances used were sodium nitrate, ammonium sulphate, asparagin (twice recrystallized) and casein hydrolysate (Ashe 'vitamin-free'), the nitrogen concentration being in each case $0.033 \%$. The rate of growth of the organism was estimated by measuring colony-diameters at intervals (Table 5). 


\section{Growth factors}

It was found that the C. globosum and the Memnoniella echinata differed in their response to some of the recognized members of the B-group of vitamins, and it will be more convenient to consider each organism separately.

Table 4. Initial concentration of glucose, concentration at time of sporulation, and time for sporulation in liquid media

Chaetomium globosum

Glucose (\%)

\begin{tabular}{ccc}
\multicolumn{3}{c}{ Glucose (\%) } \\
$\overbrace{\text { Initial }}^{\begin{array}{c}\text { At onset of sporulation, } \\
\text { or after 44 days }\end{array}}$ & $\begin{array}{c}\text { Days required for } \\
\text { sporulation }\end{array}$ \\
0.10 & $<0.015$ & 8 \\
0.30 & $<0.015$ & 18 \\
0.50 & $<0.015$ & $>44$ \\
2.00 & $<0.015$ & $>44$
\end{tabular}

Memnoniella echinata

$\begin{array}{ccc}\text { Glucose (\%) } & \begin{array}{c}\text { Days required for } \\ \text { sporulation }\end{array} \\ 0.50 & \text { At onset of sporulation } & 5 \\ 1.00 & 0.16 & 5 \\ 1.50 & 0.65 & 5\end{array}$

Table 5. Influence of various sources of nitrogen on colony diameter $(\mathrm{mm}$.$) of$ Chaetomium globosum on solid media

\begin{tabular}{|c|c|c|c|c|c|c|c|c|c|c|}
\hline & \multicolumn{10}{|c|}{ Days } \\
\hline & 1 & $\mathbf{3}$ & 4 & 5 & 6 & 7 & 8 & 10 & 11 & 18 \\
\hline Sodium nitrate & $\mathbf{1 \cdot 5}$ & 8 & 11 & $13 \cdot 5$ & $16 \cdot 5$ & 20 & 23 & $24^{*}$ & 25 & 28 \\
\hline Ammonium sulphate & O & $\mathbf{3}$ & $3 \cdot 5$ & 4 & 4.5 & 4.5 & 4.5 & $4 \cdot 5$ & 4.5 & 4.5 \\
\hline Asparagin & $1 \cdot 5$ & 8 & 10 & 12 & 14 & $16 \cdot 5$ & 19 & $27 \cdot 5$ & 32 & $38^{*}$ \\
\hline Casein hydrolysate & 1.5 & $13 \cdot 5$ & $16 \cdot 5$ & 20 & 22 & $24^{*}$ & $26 \cdot 5$ & 32 & 37 & 43 \\
\hline
\end{tabular}

M. echinata. The essential nature of biotin for this organism, established by Marsh \& Bollenbacher (1946) was confirmed in the present work. On liquid media containing $3 \%(\mathrm{w} / \mathrm{v})$ glucose, growth was insignificant, but the addition of as little as $0.002 \mu \mathrm{g}$. biotin $/ 20 \mathrm{ml}$. medium produced a noticeable response, and more than $\mathbf{5 0 0}$ times this amount seemed to be required for saturation at this concentration of glucose (Table 6).

Table 6. Effect of biotin on germination and growth of Memnoniella echinata

\begin{tabular}{lcccccc}
\multicolumn{5}{c}{ Memnoniella echinata } \\
& $\overbrace{0.0002}$ & $0 \cdot 002$ & 0.01 & 0.02 & $0 \cdot 1$ \\
Germination period (days) & 3 & 2 & 2 & 1 & 1 \\
$\begin{array}{c}\text { Dry weight of mycelium } \\
\text { after 10 days (mg.) }\end{array}$ & 6 & 10 & 76 & 113 & 154
\end{tabular}


Among other recognized members of the vitamin B group, thiamin, pyridoxin, nicotinic acid, riboflavin, pantothenic acid and $p$-aminobenzoic acid were without activity, and it appears that biotin represents the only $B$ vitamin requirement of $M$. echinata. It may be mentioned that growth on agar media, without added biotin or at very low biotin levels, was always better than on corresponding liquid media, suggesting the presence of a trace of biotin in the agar (cf. Table 2). The nature of the mycelium was markedly different at different biotin concentrations; in liquid media containing $0.01 \mu \mathrm{g} . \%$ or less, white detached colonies were formed, whereas in greater concentrations of biotin brownish gelatinous mats appeared. On agar media the type of growth was thin and spreading ('starvation' type) at low biotin concentrations.

Chaetomium globosum. During some experiments in which an aqueous extract of jute was used as a source of nitrogen, a remarkable stimulation of growth and formation of perithecia in C. globosum was noticed; and there was very ready fruiting when the organism was grown on jute fibres suspended in salt solutions. These facts suggested the intervention of some factor of the vitamin type, and led to experiments designed to test this supposition.

The extract was prepared from a 'white' jute of recent origin (Corchorus capsularis; grown at Kishoreganj, 1945) as follows. Five g. of the clean dry fibres were boiled for $30 \mathrm{~min}$. with about $100 \mathrm{ml}$. of distilled water, after which the extract was squeezed out and the fibre discarded. The liquor was evaporated on the water-bath to less than $50 \mathrm{ml}$. and filtered to remove a dark scum which formed during evaporation. The filtrate was added to $50 \mathrm{ml}$. of double strength basal salt medium, glucose and agar were added as required, and the whole made up to $100 \mathrm{ml}$. Thus $100 \mathrm{ml}$. of the final medium contained the extract from $5 \mathrm{~g}$. of jute, the actual weight of solid incorporated being about $50 \mathrm{mg}$. The effect of the jute extract on growth and fruiting, in a medium containing $1 \%$ glucose and $1.5 \%$ agar, and the results of comparative tests in which Marmite and malt extract (each at $1 \% \mathrm{w} / \mathrm{v}$ ) were used as sources of growth factors, are shown in Table 7 . In all cases growth was markedly stimulated, especially with Marmite, but fruiting was observed at a much earlier stage with jute extract, and the final crop of perithecia was very much greater. It may be pointed out also that Marmite and malt extract contributed an appreciable amount of solid matter to the medium, the jute extract much less.

The effect of pure vitamins was next studied, when it was found that thiamin, riboflavin, nicotinic acid, pyridoxin, pantothenic acid and $p$-aminobenzoic acid, in concentrations of 10,25 and $50 \mu \mathrm{g} . / 100 \mathrm{ml}$. of medium, and folic acid and inositol in concentrations of $5 \mu \mathrm{g}$. and $10 \mathrm{mg} . / 100 \mathrm{ml}$. respectively, had no significant effect on growth or fruiting. Biotin appeared to accelerate fruiting to a slight extent, but the effect was in no way comparable with that of the jute extract (Table 8).

An attempt was made to estimate the quantities of known growth substances in jute extract, with a view to simulating the effect of the extract with an artificial mixture in the correct proportions. Assays were made by the methods described by Barton-Wright (1946), except that thiamin was estimated by the method of Bonner \& Erickson (1938). On the basis of these results (Table 9), 
the pure vitamins corresponding to $5 \mathrm{~g}$. of jute were incorporated into $100 \mathrm{ml}$. of basal agar medium, containing $0.5 \%$ glucose.

This mixture, though possibly causing a slight acceleration of fruiting, was in no way as active as the crude extract from jute (Table 10).

Table 7. Effect of Marmite, malt extract and jute extract on growth and sporulation of Chaetomium globosum

(a) Colony diameters (mm.) on agar media

\begin{tabular}{|c|c|c|c|c|c|c|c|c|c|}
\hline & & & & & ays & & & & \\
\hline & 1 & 2 & 3 & 4 & 5 & 6 & 7 & 10 & 14 days \\
\hline Marmite & $2 \cdot 5$ & 12 & $13^{*}$ & 28 & 30 & 31 & $\mathbf{3 2} \cdot 5$ & 46 & ++ \\
\hline Malt extract & 3 & 10 & $10^{*}$ & 25 & 27 & $27 \cdot 5$ & 28 & $34 \cdot 5$ & $\underset{\text { (Immature) }}{+}$ \\
\hline Jute extract & $3 \cdot 5$ & 16 & $33^{*}$ & 40 & 47 & 52 & $55 \cdot 5$ & 60 & +++ \\
\hline
\end{tabular}

(b) Dry weight of mycelium (mg.) in liquid media

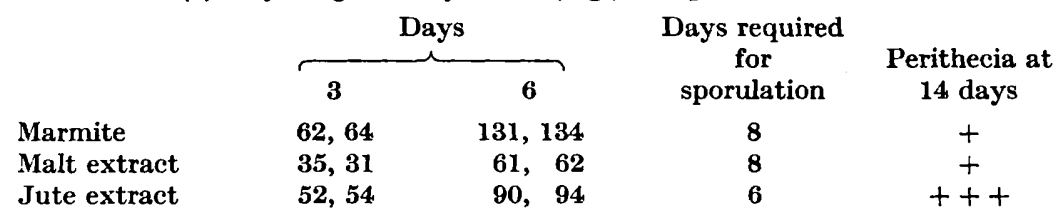

Table 8. Effect of biotin on sporulation of Chaetomium globosum on solid media

Glucose (\%) Biotin ( $\mu \mathrm{g} . \%)$ Day of fruiting

$\begin{array}{ccc}0.5 & 0 & 8-10 \\ & 4 & 6-9 \\ 1 \cdot 0 & 0 & 11-12 \\ 1.5 & 4 & 9-11 \\ & 0 & 15 \\ & 4 & 10-12\end{array}$

Table 9. Assay of vitamins in jute extract

Vitamin

Thiamin

Riboflavin

Pyridoxin

Nicotinic acid

Pantothenic acid

Biotin

$\begin{array}{ll}\begin{array}{c}\text { Mode of com- } \\ \text { putation }\end{array} & \boldsymbol{\mu g} \cdot \begin{array}{c}\text { vitamin } / \mathrm{g} . \\ \text { jute }\end{array} \\ \text { Direct reading } & \mathbf{0 \cdot 2 2 2} \\ \text { Slope-ratio } & \mathbf{0 \cdot 3 0 1} \\ \text { Slope-ratio } & \mathbf{0 \cdot 1 1 6} \\ \text { Direct reading } & \mathbf{0 . 4 7 1} \\ \text { Direct reading } & \mathbf{0 . 2 5 9} \\ \text { Direct reading } & \mathbf{0 . 0 0 8 9}\end{array}$

Estimations of residual sugar at the time of fruiting again showed that exhaustion of soluble sugar was in some way connected with sporulation; at all concentrations of glucose, fruiting was much accelerated, and this was especially so when the initial glucose was $2 \%$ or more, as previous experiments, using media without added growth factors, had failed to give fruiting even after 44 days (Table 11, cf. Table 4). 
The rate of glucose utilization in media containing initially $0.25 \%$ of the sugar was determined in presence and in absence of jute extract. The results (Fig. 1) indicated that sugar consumed per unit weight of mycelium remained fairly constant throughout the entire growth period, and was the same on both

Table 10. Comparison of the effect of jute extract and mixed vitamins on colony diameters ( $\mathrm{mm}$.) of Chaetomium globosum (solid media)

\begin{tabular}{|c|c|c|c|c|c|c|c|c|c|c|}
\hline & \multicolumn{10}{|c|}{ Days } \\
\hline & i & 2 & $\mathbf{3}$ & 5 & 6 & 7 & 8 & 9 & 10 & 12 \\
\hline Basal medium & $\mathbf{0}$ & $\mathbf{3} \cdot \mathbf{5}$ & $6 \cdot 5$ & 13 & 17 & $20 \cdot 5$ & $\mathbf{2 3}$ & 25* & 27 & $28 \cdot 5$ \\
\hline Mixed vitamins & o & 4 & 6.5 & $11 \cdot 5$ & 14 & 19 & $22^{*}$ & 25 & 27 & 30 \\
\hline Jute extract & 3 & 15 & $26 *$ & 44 & 51 & 57 & 64 & 69 & 75 & - \\
\hline
\end{tabular}

Table 11. Chaetomium globosum in liquid media; concentration of glucose at time of sporulation in presence of jute extract

$\begin{array}{ccc}\text { Initial } & \text { At onset of fruiting } & \begin{array}{c}\text { Days required for } \\ \text { fruiting }\end{array} \\ 0.10 & <0.015 & 5 \\ 0.30 & <0.015 & 5 \\ 0.50 & <0.015 & 7 \\ 1.00 & <0.015 & 11 \\ 2.00 & <0.015 & 22\end{array}$

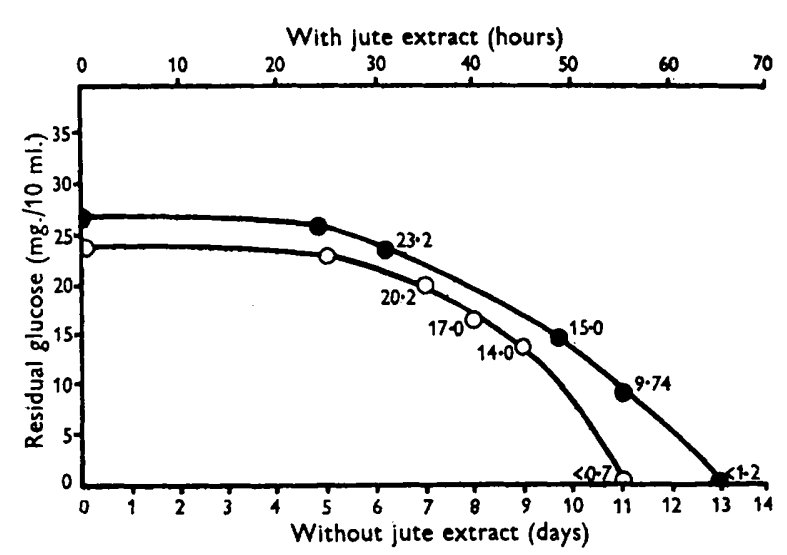

Fig. 1. The rate of sugar consumption by Chaetomium globosum in liquid media.

presence of jute extract, $\mathrm{O}-\mathrm{O}$ in absence of jute extract.

media. In each case the rate of consumption increased till the end, and fruiting was preceded by the period of most rapid utilization. Jute extract, by stimulating growth, greatly increased the rate and perithecia appeared sooner.

These observations suggested that fruiting was stimulated by the action of some definite chemical substance, present in notable amounts in jute, but not any one of the six vitamins assayed or of the other three tested. Such a substance might be slowly produced by the organism itself, attainment of 
a critical concentration being necessary for fruiting. If such were the case, an extract of a vigorously fruiting culture might stimulate sporulation in a vegetative culture, or it might be possible to detect such a substance in the surrounding medium. To test this, Chaetomium globosum was grown in $200 \mathrm{ml}$. of liquid medium containing $0.1 \%$ of glucose; the mycelium was harvested on the tenth day, when fruiting was vigorous, and an extract was made by grinding up the mycelium with $40 \mathrm{ml}$. of fresh basal medium. This extract was filtered and incorporated in a fresh batch of medium, with $0.5 \%$ glucose. Similarly, the staled liquid medium was adjusted to its original $\mathrm{pH}(5 \cdot 8)$ and the glucose concentration brought to $0.5 \%$. In each case $1.5 \%$ agar was added, and after sterilization fresh inoculations were made. Table 12 shows the relative growth and fruiting properties of the original medium and those incorporating mycelial extract or metabolic products.

Table 12. Effect of mycelial extract and staled medium on colony diameters (mm.) of Chaetomium globosum on solid media

\begin{tabular}{|c|c|c|c|c|c|c|c|c|}
\hline & \multicolumn{8}{|c|}{ Days } \\
\hline & 1 & $\mathbf{2}$ & $\mathbf{8}$ & 4 & 7 & 8 & 9 & 10 \\
\hline Basal medium & $\mathbf{0}$ & $\mathbf{3 \cdot 5}$ & 6.5 & - & $20 \cdot 5$ & 23 & 25* & 27 \\
\hline Mycelial extract & $\mathbf{3} \cdot \mathbf{5}$ & $7 \cdot 0$ & $10 \cdot 5$ & 14 & $26^{*}$ & 81 & 34 & 35 \\
\hline Staled medium & $\mathbf{2 \cdot 5}$ & 6.5 & 8.5 & 13 & 25* & 27 & 31 & $\mathbf{3 4}$ \\
\hline
\end{tabular}

\section{Influence of contaminant fungi}

The mutual stimulation of organisms growing in association is well known and can usually be ascribed to the production by each of the species of a growth factor essential for the other (cf. Kögl \& Fries, 1937). Tests were accordingly made to discover whether other fungi could stimulate fruiting in $C$. globosum or Memnoniella echinata grown on agar media containing $0.5 \%$ glucose. Fifteen species, all of which except the Memnoniella sp. grew and sporulated well on defined media, were tried on Chaetomium globosum; these included four species of Aspergillus, five of Penicillium, one each of Trichoderma, Paecilomyces, Chaetomium, Stachybotrys and Memnoniella, and another Dematiaceae species. The test fungus was planted 2 days before the Chaetomium globosum. In no case was any stimulation of fruiting observed, and perithecia when they appeared always began to develop from the centre of the colony, and not at the edge nearest the contaminant organism. With Memnoniella echinata, on the other hand, the presence of any one of a wide variety of fungi induced fruiting at the edge nearest to the foreign colony.

\section{DISCUSSION}

From previous work, as well as from that recorded here, it is evident that many factors, both chemical and physical, may affect the processes whereby the mycelial habit of growth gives place to the sporulating. Among other factors must be counted: (a) the degree of 'maturity' of the organism; $(b)$ the general 
nutritional level, especially perhaps as regards carbohydrate supply; and $(c)$ the possible action of certain stimulants necessary in minute amounts and thus resembling (or in some cases perhaps identical with) the long recognized growth factors.

That the organism must attain a certain state of development before fruiting can occur seems to be unquestionable; for instance, on a $0.5 \%$ glucose medium, Chaetomium globosum never produced perithecia until the colonies had reached a diameter of some $20 \mathrm{~mm}$. irrespective of whether this occurred in 3 or in 10 days. The suggestion that some substance formed by the organism itself must reach a critical concentration to induce fruiting receives some support from the observation that fruiting is accelerated by extracts of the mature organism.

The experiments on sugar utilization indicate that the general nutritional level, especially as regards carbohydrates, is implicated; for with $C$. globosum in liquid media, fruiting was in every case delayed till the free sugar in the medium had been reduced to a very low concentration, either owing to almost complete utilization, or because soluble sugar was available only at low concentrations as a result of its slow liberation from a polysaccharide. Previous workers have recorded that media of low sugar content favour fruiting in many fungi (cf. Hawker \& Chaudhury, 1946). The apparent anomaly (Tables $7(a)$ and 9) that the organism continues to grow in agar media after the onset of sporulation, and may more than treble the diameter of colonies, is explained by the slow diffusion of sugar in the agar; the perithecia form in the centre of the colony, where sugar approaches exhaustion, while fresh growth takes place at the periphery.

It is clearly possible that certain chemical substances may be necessary for the initiation of sporulation. The influence of thiamin and biotin on fruiting in various species has been made evident during the past decade, and the effect of biotin on Memnoniella echinata again appears here. Among the carbohydrates examined, it is perhaps significant that those which at first sight seemed to be associated with rapid production of perithecia were all colloidal substances of high molecular weight, prepared from plant material, upon which traces of growth substances from the plant tissue might well remain adsorbed. Maltose, an apparent exception to this, has been shown by Schopfer $(1932,1934)$ to be liable to contamination with thiamin.

Increased growth was frequently found to result from the presence of various 'natural' extracts (malt, yeast, etc.) in the media, and in some cases an appreciable acceleration of fruiting was also observed; even an extract of agar gave a small response in liquid media. The presence of members of the B-group may well have accounted for the increased growth, but none except perhaps biotin directly affects sporulation. Of all the materials tested, the extract of jute is outstanding in stimulating the formation of perithecia in Chaetomium globosum, not only in the shortest time, but also in the greatest quantity, and suggests the existence of a definite 'fruiting factor' other than the recognized B-group vitamins. Only biotin, of all the known substances tested, had any detectable effect on the fruiting of $C$. globosum. This substance is almost 
certainly produced and liberated by many fungi, as shown by the stimulatory effect of many species grown in association with Memnoniella echinata, for which it is the only essential growth factor; yet none of the species which were found to stimulate $M$. echinata had the least effect on Chaetomium globosum. The factor in jute is therefore not biotin, nor any other of the nine B-vitamins tested.

Such a substance may accelerate sporulation merely by causing a more rapid utilization of sugar, for instance, by stimulating respiration (since exhaustion of sugar seems a prerequisite of fruiting in Chaetomium); or it may act in a more specific and direct manner, that is, by taking part in some enzyme system immediately concerned in the differentiation of the fruit bodies. That such factors are confined to jute is by no means suggested. Robbins \& Ma (1942) found in cotton not only biotin and pyridoxin, but also unknown factors 'favourable to Ceratostomella', while Zuck \& Diehl (1946) demonstrated that certain other species grew and fruited on cotton-extract media, but not on defined media (see also Sherwood \& Singer, 1944). A small amount of some stimulant apparently occurs in agar, and Tschudy's (1937) finding that Chaetomium species fruited better on agar media than in liquid would seem due to such factors, and not to the action of nutrients such as pentosans, as he suggests. The observation that extracts of mature mycelia, or of staled media, accelerate fruiting not only indicates that a definite chemical influence is at work, but is again in agreement with the suggestion that the 'fruiting factor' may be distinct from the recognized growth factors.

Memnoniella echinata differs in some important respects from Chaetomium globosum. In the first place, biotin is essential for growth. In its presence in adequate amounts, exhaustion of sugar is not an essential prerequisite for sporulation; nevertheless, with very low levels of biotin, sporulation is connected with low levels of soluble sugar. If fruiting is initiated directly by a chemical stimulant other than biotin, then this must be produced in sufficient quantities by the organism itself; no indication of any other external factor was detected, and even the jute extract, so active for $C$. globosum, had no more effect than could be ascribed to its biotin content. One anomaly remains to be mentioned. The method of preparation of cello-dextrin, involving fairly drastic chemical processes (e.g. acetolysis), was expected to destroy any biotin present in the original cellulose; nevertheless, cello-dextrin distinctly stimulated growth and sporulation, and the possibility still remains that some at least of the high-molecular polysaccharides may have their own influence on metabolism.

The authors wish to record their thanks to the Committee of the Indian Jute Millers' Association Research Institute, by whom the work was supported, and to Dr S. E. Jacobs and Dr L. E. Hawker, for helpful discussion.

\section{REFERENCES}

Barton-Wright, E. C. (1946). Practical Methods for the Micro-biological Assay of the $B$ Complex and essential Amino-acids. London: Ashe.

Bonner, J. \& Erickson, J. (1938). The Phycomyces assay for thiamin. Amer. J. Bot. 25, 685 . 
Coons, G. H. (1916). Factors involved in growth and pycnidium formation of Plenodomus fascomaculans. J. agric. Res. 5, 713.

Hawker, L. E. \& Chaudhury, S. D. (1946). Growth and fruiting of certain ascomycetous fungi, as influenced by the nature and concentration of carbohydrate in the medium. Ann. Bot., Lond., 10 (N.S.), 185.

KLebs, G. (1900). Zur Physiologie der Fortpflanzung einiger Pilze. Jb. wiss. Bot. $35,80$.

Kögl, F. \& Fries, N. (1937). Über den Einfluss von Biotin, Aneurin und mesoInosit auf das Wachstum verscheidenen Pilzarten. Hoppe-Seyl. Z. 93, 249.

Marsh, P. B. \& Bollenbacher, K. (1946). The vitamin requirements of Memnoniella and Stachybotrys. Amer. J. Bot. 33, 245.

Robbins, W. J. \& MA, R. (1942). Vitamin deficiencies of Ceratostomella. Bull. Torrey bot. $\mathrm{Cl} .69,182$.

Robinson, W. (1926). The conditions of growth and development in Pyronoma confluens Tul. Ann. Bot., Lond., 40, 245.

Schopfer, W. H. (1932). Récherches expérimentales sur la formation de zygotes chez Phycomyces blakesleeanus. Ber. schweiz. bot. Ges. 41, 73.

Schopfer, W. H. (1934). Les vitamins $B$ comme hormones de croissance chez un micro-organisme. Arch. Mikrobiol. 5, 511.

Sherwood, M. B. \& Singer, E. D. (1944). Folic acid in cotton. J. biol. Chem. 155,361 .

Tschudy, R. H. (1937). Experimental morphology of some species of Chaetomium. Amer. J. Bot. 24, 472.

ZucK, R. K. \& DreHL, W. W. (1946). On fungal damage to sun-exposed cotton duck. Amer. J. Bot. 33, 374.

\section{ADDENDUM}

Note on the biotin requirements of Stachybotrys atra

A culture of Stachybotrys atra (kindly supplied by Mr L. D. Galloway), while giving only a poor mycelial growth on a liquid medium containing $3 \%$ glucose, was found to grow well and to produce abundant conidia in agar media, and in liquid media when the glucose was replaced by filter-paper. Marsh \& Bollenbacher (1946) reported a partial deficiency of biotin in this organism, and the above observations are in agreement with this view.

\section{EXPLANATION OF PLATE}

Chaetomium globosum grown on agar containing inorganic salts and $1 \%$ glucose. Petri dishes $7 \cdot 5 \mathrm{~cm}$. diameter.

Fig. 1. Growth and sporulation after 6 days. Left to right, the basal medium alone, with $1 \%$ malt extract, and with extract of $5 \mathrm{~g}$. jute/100 ml.

Fig. 2. Growth and sporulation after 14 days. Left to right, basal medium with $1 \%$ malt extract, with $1 \%$ marmite, and with extract of $5 \mathrm{~g}$. jute/100 ml. 
Journal of General Microbiology, Vol. 2, No. 2

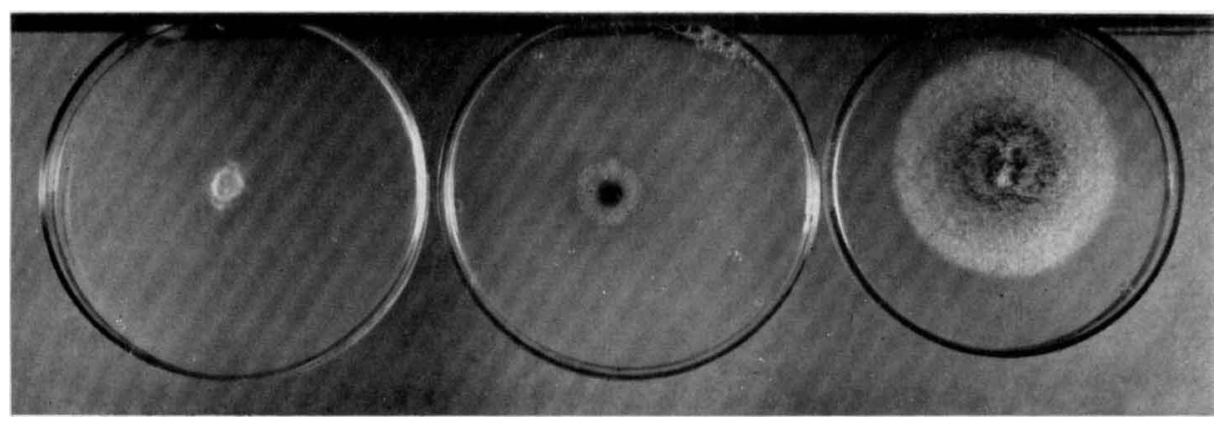

Fig. 1

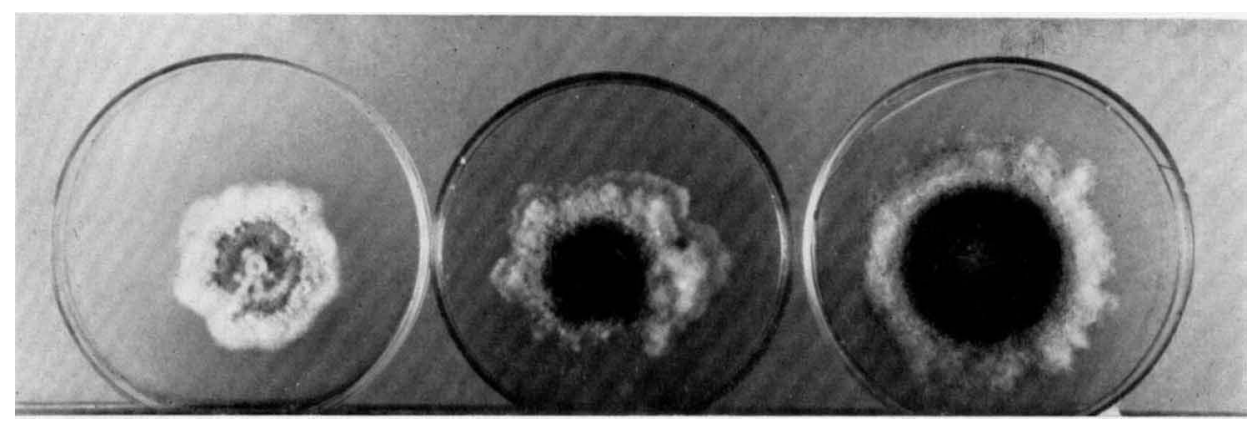

Fig. 2

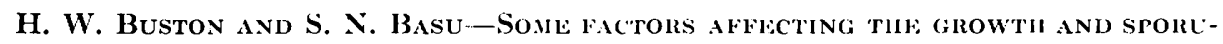

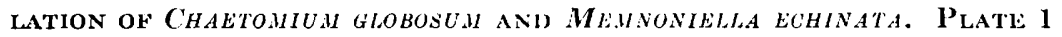

